\title{
Modeling and Characterization of Low Voltage Access Network for Narrowband Powerline Communications
}

\author{
Bilal Masood ${ }^{\dagger}$, Arsalan Haider* and Sobia Baig**
}

\begin{abstract}
Nowadays, Power Line Communication (PLC) is gaining high attention from industry and electric supply companies for the services like demand response, demand side management and Advanced Metering Infrastructure (AMI). The reliable services to consumers using PLC can be provided by utilizing an efficient PLC channel for which sophisticated channel modeling is very important. This paper presents characterization of a Low Voltage (LV) access network for Narrowband Power Line Communications (NB-PLC) using transmission line (TL) theory and a Simulink model. The TL theory analysis not only includes the constant parameters but frequency selectivity is also introduced in these parameters such as resistance, conductance and impedances. However, the proposed Simulink channel model offers an analysis and characterization of capacitive coupler, network impedance and channel transfer function for NB-PLC. Analysis of analytical and simulated results shows a close agreement of the channel transfer function. In the absence of a standardized NBPLC channel model, this research work can prove significant in improving the efficiency and accuracy of NB-PLC communication transceivers for Smart Grid communications.
\end{abstract}

Keywords: Advanced metering infrastructure, NB-PLC, Capacitive coupler

\section{Introduction}

The emerging smart grid (SG) technologies aim to monitor the flow of energy intelligently through a reliable communication system. Merging a communication network with the monitoring infrastructure to measure and analyze the energy consumption involves an advanced metering infrastructure (AMI) in SG [1]. The communication network may be based on wireless or a wired communication medium. The wired PLC network offers a ubiquitously available network and is one of the most promising communication technologies for AMI because of its already existing infrastructure. The LV access network in the narrowband frequency range may serve to facilitate AMI data communication. NB-PLC standards for low voltage access network are based on various communication technologies that have emerged in the recent past, such as IEEE 1901.2, PRIME (ITU-T G.9904) and G3-PLC (ITU-T G.9903) [2]. However, design and performance of a reliable communication system requires essential information about channel condition. Powerline is an unpredictable and noisy communication channel. PLC channel causes attenuation in the communication signal, which depends on length of power line. Moreover, local geographical topology and

$\dagger$ Corresponding Author: Dept. of Electrical Engineering, COMSATS Institute of Information Technology, Lahore, Pakistan. (bilalmasood84@yahoo.com)

* Dept. of Electrical Engineering, The Superior College, University Campus, Lahore, Pakistan. (arsalanhaider9262@gmail.com)

** Dept. of Electrical Engineering, COMSATS Institute of Information Technology, Lahore, Pakistan. (drsobia@ciitlahore.edu.pk)

Received: October 13, 2015; Accepted: April 4, 2016 configuration of power grid differ from country to country causing large variations in PLC channel transfer function and researchers find it difficult to standardize [3].

In the context of implementation of NB-PLC on power lines, it is quite different from traditional communication networks. Because before installation and deployment of NB-PLC infrastructure it is particularly important to design and model the power line channel on which communication take place along with the proper analysis and evaluation of channel characteristics. Main characteristic of power line channel includes the impedance matching and its continuously varying nature with respect to change in frequencies of the signal, channel multipath delay that lead to drop the quality of communication signal and various type of noises. After a thorough literature review on PLC channel models it has been observed that several channel models are presented based on various channel conditions and configurations [1, 4-6]. Since PLC based communication systems may operate in various frequency bands, and variable channel noise conditions, not one approach of channel modeling and model is applicable to all scenarios. Therefore it is important to model various specific channel conditions on a channel model.

Channel modeling of PLC is categorized into three sections on the basis of opted methodology, model type, simulation and performed field measurements. Zimmermann in [7] presented a multipath model for power line channel in which he derived the complex frequency response of PLC channel for the frequency range $500 \mathrm{kHz}$ to $20 \mathrm{MHz}$. $\mathrm{He}$ derived the results by taking physical effects like 
muultipath signal propagation and typical cable losses into consideration. The presented model was analytical model that describes the complex transfer functions of typical power line networks by using only a small set of parameters. The model does not serve the complete set of parameters required for a channel models. Andrea M. Tonello proposed statistical bottom up PLC channel modeling by using random topology technique for obtaining the transfer function utilizing the computational efficiencies in [8]. He first derived the results of European in-home network topology by practicing the statistical approach then he proposes a novel method that can determine the transfer function between any pairs of outlets of a given topology. In [9, 10], Tonello presents a simulator that can be used to configure a small set of parameters for theoretical framework. The simulator is used to study and investigate the properties of PLC channel statistically.

In reference to deterministic channel modeling of PLC, Stefano Galli has produced significant research work. Galli published [5] and [6] simultaneously in two parts by focusing on the indoor PLC channels. He conducted his research on circuit analysis along with its companion model in [5]. Galli addressed the problem of indoor power line channel by its proper modeling based on multiconductor transmission lines (MTL) theory and model decomposition. He followed MTL approach that ultimately leads to a model consisting of two coupled circuits representing the propagation interaction of the two dominant modes called differential and pair mode. The differential model basically caters the differential propagation of signals and companion model account for the excitation and propagation of pair mode. Author concludes in [5] that, by neglecting the mode coupling and therefore the companion circuit lead to an incomplete circuit model that is not capable of representing the physics of signal propagation on power line cables specifically for PLC.

In [6] Galli presented a novel approach for the modeling of indoor power line channel in which he elucidated and calculated the transfer function and properties of power line channel. He crossed several levels of abstractions before locating a useful and accurate model for indoor power line channel. In [6], he uses the differential and companion models as a cascaded two port networks. Each of these networks is represented by their parameters by utilizing the transmission matrix techniques. He suggested that distributed parameter of circuits can be considered or replaced by a single lumped network for the ease of analysis and calculations. He also proved mathematically and then experimentally that indoor power line regardless of its topology exhibits the same transfer function from either side. In the research trials he concluded with the fact that the only condition required for the symmetry is that the source and load impedances should be the same or the output impedance of transmitter should be equal to input impedance of receiver. Furthermore he experimentally observed that it is possible to isolate the reflections and resonant modes on the basis of specific topologies.

In [4] Sung, Anna Scaglione and Stefano Galli expanded their research by evaluating the time varying nature of power line. They highlighted the fact that power line channel may vary abruptly with respect to the layout of topology. They incorporated the fact that due to the switching of appliances and devices installed indoor, variations take place in the characteristics of power lines. These variations are caused due to the continuously varying impedances that is linked with the instantaneous amplitude of the mains voltage which in turn results in a periodically time-varying channel response. Similarly in [11] and [12] Anatory analysis the power line channel by following the aforementioned approach of Galli, the only difference in the evaluation is conductor schemes. He evaluated the power line channel model by incorporating the two conductor and multiconductor concept.

After a critical literature review and results discussion of several authors, PLC channel has been modeled using various approaches presented in literature, which encompass the top down and bottom up approaches [6]. This research work presents a novel model of a LV powerline channel using TL theory and NB-PLC Simulink model for an outdoor low voltage NB-PLC. We have introduced a capacitive coupler in the NB-PLC channel model. We have also analyzed the effect of constant and frequency selective impedances on transfer function of PLC channel using the TL theory and compared the results obtained from a Simulink model. This paper is organized as follows. Section 2 elaborates the NB-PLC system along with proposed TL theory, Simulink model and capacitive coupling device. Section 3 describes the results and discussions of channel transfer functions followed by conclusions.

\section{Narrowband Powerline Communication System}

In this research paper channel modeling of LV TLs for Narrowband Powerline Communication is presented that supports the low data rate applications used for smart metering, AMI and control purposes. We have modeled a LV access network for NB-PLC that consists of a distribution transformer, transmission line, branches and three phase RLC loads depicting the behaviour of consumers. Fig. 1 shows the NB-PLC system model in which power flows from medium voltage (MV) to LV network. NB-PLC signal is injected through a coupling device (CD) located at the last consumer's end that is 150 $\mathrm{m}$ away from MV to LV transformer and received at the LV side of transformer. The capacitive coupler is designed to couple the signal between transmitter and LV network, and an identical coupler is used at the receiving end [3]. A number of branches emanate from the main channel representing the consumers between transmitter and receiver, effect of which is incorporated on the overall transfer function of the proposed channel model. A TL 
Table 1. Electrical parameters of conductors

\begin{tabular}{c|c|c|c|c|c|c|c}
\hline $\begin{array}{c}\text { Conductor Type/ } \\
\text { Standard }\end{array}$ & $\begin{array}{c}\text { Nominal/Section } \\
\text { Area }\end{array}$ & $\begin{array}{c}\text { No./Nominal diameter } \\
\text { of wires }\end{array}$ & $\begin{array}{c}\text { Approximate Overall } \\
\text { Diameter }\end{array}$ & $\begin{array}{c}\text { Nominal DC Resistance } \\
\text { at } 20^{\circ} \mathrm{C}\end{array}$ & $\begin{array}{c}\text { Current } \\
\text { Rating }\end{array}$ & L & C \\
\cline { 2 - 8 } & $\mathrm{mm}^{2}$ & No./mm & $\mathrm{mm}$ & $\Omega / \mathrm{km}$ & $\mathrm{Amps}$ & $\mu \mathrm{H} / \mathrm{m}$ & $\mathrm{pF} / \mathrm{m}$ \\
\hline Wasp-BS 215 & 100 & $7 / 4.39$ & 13.17 & 0.2720 & 286 & 0.86 & 13.6 \\
\hline PVC-BS 6485 & 14 & $7 / 1.60$ & 6.8 & 1.3030 & 56 & 0.59 & 38 \\
\hline
\end{tabular}

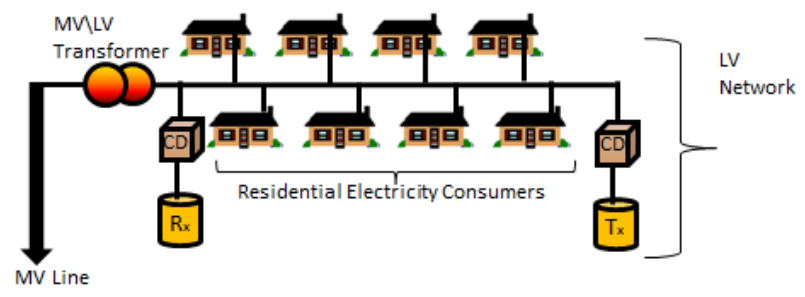

Fig. 1. NB-PLC system model

theory and Simulink channel model based on the NB-PLC system described here is discussed in the subsequent subsections.

\subsection{Transmission line theory model of NB-PLC channel}

In this Section, we have presented the transmission line theory model of NB-PLC channel based on actual transmission line parameters that is all aluminum conductors (AAC), standard BS-215, code name Wasp, with ampacity up to $286 \mathrm{~A}$. The electrical properties of any segment of TL are determined by its distributed parameters such as resistance $R$, conductance $G$, inductance $L$ and capacitance $\mathrm{C}$. In this research work the chosen frequency range is $3-500 \mathrm{kHz}$. According to TL theory, propagation constant $\gamma$ and characteristic impedance $Z_{C}$ of a TL can be described as,

$$
\begin{gathered}
\gamma=\alpha+\beta=\sqrt{(R+j \omega L)(G+j \omega C)} \\
\mathrm{Z}_{\mathrm{C}}=\sqrt{(\mathrm{R}+\mathrm{j} \omega \mathrm{L}) /(\mathrm{G}+\mathrm{j} \omega \mathrm{C})}
\end{gathered}
$$

where $\alpha$ and $\beta$ are real (attenuation constant in $\mathrm{Np} / \mathrm{m}$ ) and imaginary (phase constant in $\mathrm{rad} / \mathrm{m}$ ) parts of the propagation constant $\gamma$ and $\omega$ is the angular frequency of powerlines under evaluation.

The per unit length capacitance and inductance of channel are not frequency dependent unlike resistance and conductance. Frequency selectivity of resistance and conductance that usually occurs due to skin effect in transmission lines has been introduced in LV network to better estimate the cable and conductors losses which are given by [13],

$$
\begin{aligned}
& R=R_{d c} \cdot 10^{-5} \cdot \sqrt{f}(\Omega / m) \\
& G=G_{0} \cdot 10^{-14} \cdot 2 \pi f(S / m)
\end{aligned}
$$

where $f$ represents the frequency in Hz whereas $R_{d c}$ and

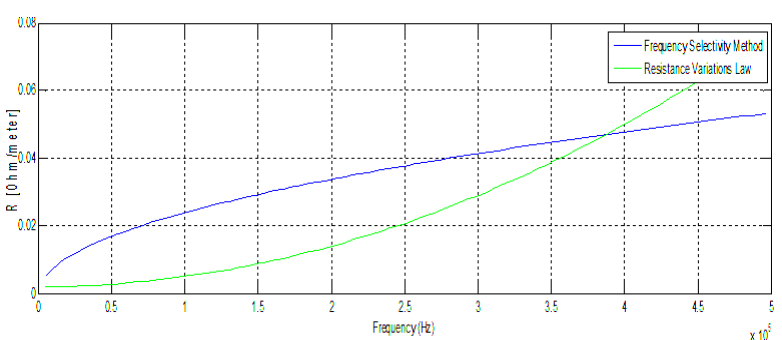

Fig. 2. Frequency selectivity of conductor's resistance

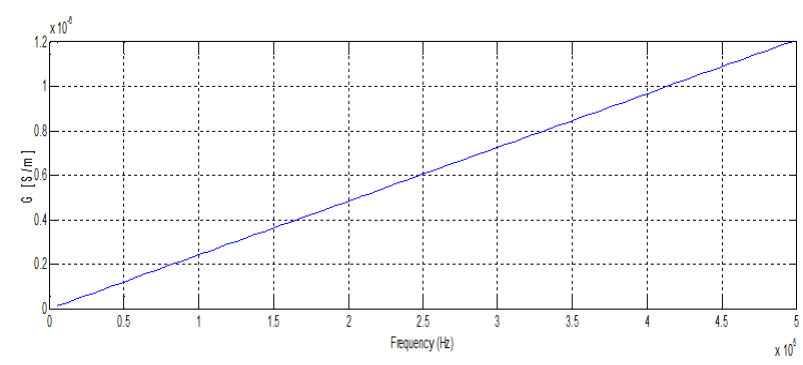

Fig. 3. Frequency selectivity of conductor's conductance

$G_{0}$ are resistance and conductance of conductor.

In this research work each bridge tap is a residential electricity consumer as illustrated in Fig. 1. In TL theory model eight bridge taps are connected between source and load impedances. The conductor type used for bridge taps in both TL theory and developed Simulink model is Polyvinyl Chloride (PVC) copper cable with crosssectional area of $14 \mathrm{~mm}^{2}$. The values of $R_{d c}$ and $G_{0}$ of each bridge tap is taken as $1.3030 \Omega$ and $52 S$ respectively. For overhead lines, $R_{d c}$ is $0.2720 \Omega$ and $G_{0}$ is close to zero because insulating material between conductors is free space. The electrical parameters of conductors used in main channel that is AAC, BS-215 type and each bridge tap for both TL theory and proposed Simulink model are tabulated in Table 1. It is concluded that frequency selective resistance modeled with equation 3 is also obeying the resistance variations law [3],

$$
R(f)=A_{R} f^{2}+B_{R} f+C_{R}
$$

where values of $A_{R}$ is $2 \times 10^{-11} \mathrm{~m} \Omega /\left(\mathrm{m}^{*} \mathrm{kHz} z^{2}\right), B_{R}$ is $1 \times 10^{-11}$ $m \Omega / m * k H z^{2}$ and $C_{\mathrm{R}}$ is $2 \mathrm{~m} \Omega / \mathrm{m}$. Figs. 2 and 3 illustrates the resistance and conductance variations of PVC conductors with respect to frequency in which Fig. 2 elucidates the resistance variations obtained from both methods. In all, both resistance and conductance display an increase with increase in frequency.

The inductance of each phase and capacitance can be 
calculated as [14],

$$
\begin{gathered}
L_{a}=2 \times 10^{-7} \ln (G M D / G M R) H / m \\
C=\frac{2 \pi \varepsilon_{0}}{\ln (G M D / r)} F / m
\end{gathered}
$$

where $\varepsilon_{0}$ is $8.85 \times 10^{-12}$. The values of geometric mean distance (GMD) and geometric mean radius (GMR) are calculated as,

$$
\begin{gathered}
G M D=\sqrt[3]{D_{12} D_{23} D_{31}} \\
G M R=r e^{-\frac{1}{4}}
\end{gathered}
$$

where $r$ is radius of conductor and $D_{12}, D_{23}, D_{31}$ are distance between conductors of two phases $\mathrm{AB}$ (11 inches), $\mathrm{BC}$ (11 inches) and CA (22 inches) for overhead LV main channel respectively.

Impedance modeling is a critical part for NB-PLC due to the frequency selectivity of channel and electricity consumers connected to the grid in form of bridge tap impedances and load impedances. The behavior of various electrical appliances thus residential electricity consumers reveals the fact that loads can be classified into two main types: constant impedances and frequency selective impedances [15]. Both types of loads are considered independently in TL theory model and their corresponding transfer functions are compared which both are further compared with the transfer function obtained from proposed Simulink model. The appropriate values of constant impedances that are constant residential loads connected to LV network are taken with any random constant value between 4-8 $\Omega$. However frequency selective impedances which are considered more practical while taking the real model are more accurate because they vary with increase in frequency. Frequency selective nature of variable loads that corresponds to residential electricity consumers connected to LV network in our case can be represented by modeling a parallel resonant RLC circuit as [13],

$$
Z(\omega)=\frac{R}{1+j Q\left(\frac{\omega}{\omega_{0}}-\frac{\omega_{0}}{\omega}\right)}
$$

where $Q$ is a quality factor (selectivity), $R$ represents the resistance at resonance and $\omega_{0}$ is representing angular resonant frequency. The average plot for frequency selective behavior of each residential load connected to the LV network which varies with respect to frequency is shown in Fig. 4. It is worth noticing that average impedance of each residential load varies between 4-8 $\Omega$ with respect to frequency. The equivalent input impedance $Z_{\text {in }}$ of LV network connected between transmitter and receiver is calculated as [16],

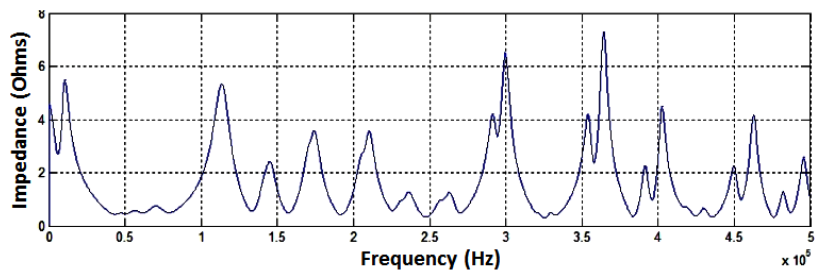

Fig. 4. Impedance variations of Electricity Consumers

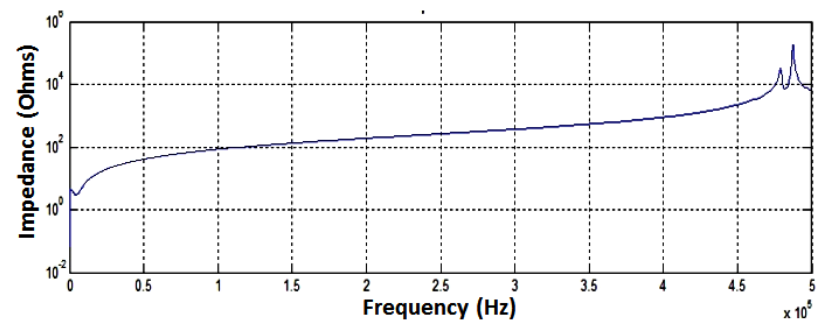

Fig. 5. Input impedance of LV Network

$$
Z_{\text {in }}=Z_{c b t} \frac{Z_{b t}+Z_{c b t} \tanh \left(\gamma_{b t} l_{b t}\right)}{Z_{c b t}+Z_{b t} \tanh \left(\gamma_{b t} l_{b t}\right)}
$$

where $Z_{b t}$ is the impedance of bridge tap offered by connected residential electricity consumers with main LV powerline channel, $Z_{c b t}$ represents characteristic impedance of bridge tap, $l_{b t}$ is length of bridge tap and $\gamma$ is the propagation constant of bridge tap. The input impedance of LV network is shown in Fig. 5 [17-18].

Magnitude of source impedance $Z_{S}$ is $50 \Omega$ whereas load impedance is $4 \Omega$ in case of constant impedance and 4-8 $\Omega$ frequency selective in case of frequency selective impedance as depicted in Fig. 4. The length of main channel and each bridge tap is $150 \mathrm{~m}$ and $15 \mathrm{~m}$ respectively.

Subsequent to the discussion of TL parameters and their variations with frequency, TL theory is applied to model the transfer function of LV access channel. Each segment of power grid can be approximated by utilizing the approach of ABCD matrix of TL parameters which establishes a relationship of sending end voltage $V_{1}$ and current $I_{1}$ with the receiving end voltage $V_{2}$ and current $I_{2}$ given as [19],

$$
\left[\begin{array}{c}
V_{1} \\
I_{1}
\end{array}\right]=\left[\begin{array}{lr}
\cosh (\gamma l) & Z_{C} \sinh (\gamma l) \\
\frac{1}{Z_{C}} \sinh (\gamma l) & \cosh (\gamma l)
\end{array}\right]\left[\begin{array}{l}
V_{2} \\
I_{2}
\end{array}\right]
$$

According to TL theory every part of TL can be modeled in form of an appropriate two port network and their transfer function can be obtained as:

$$
H=20 \log _{10} \frac{Z_{L}}{A Z_{L}+B+C Z_{L} Z_{S}+D Z_{S}}
$$

where, $Z_{S}$ and $Z_{L}$ are source and load impedances respectively, whereas $A, B, C$ and $D$ represents the $\cosh (\gamma l)$, 


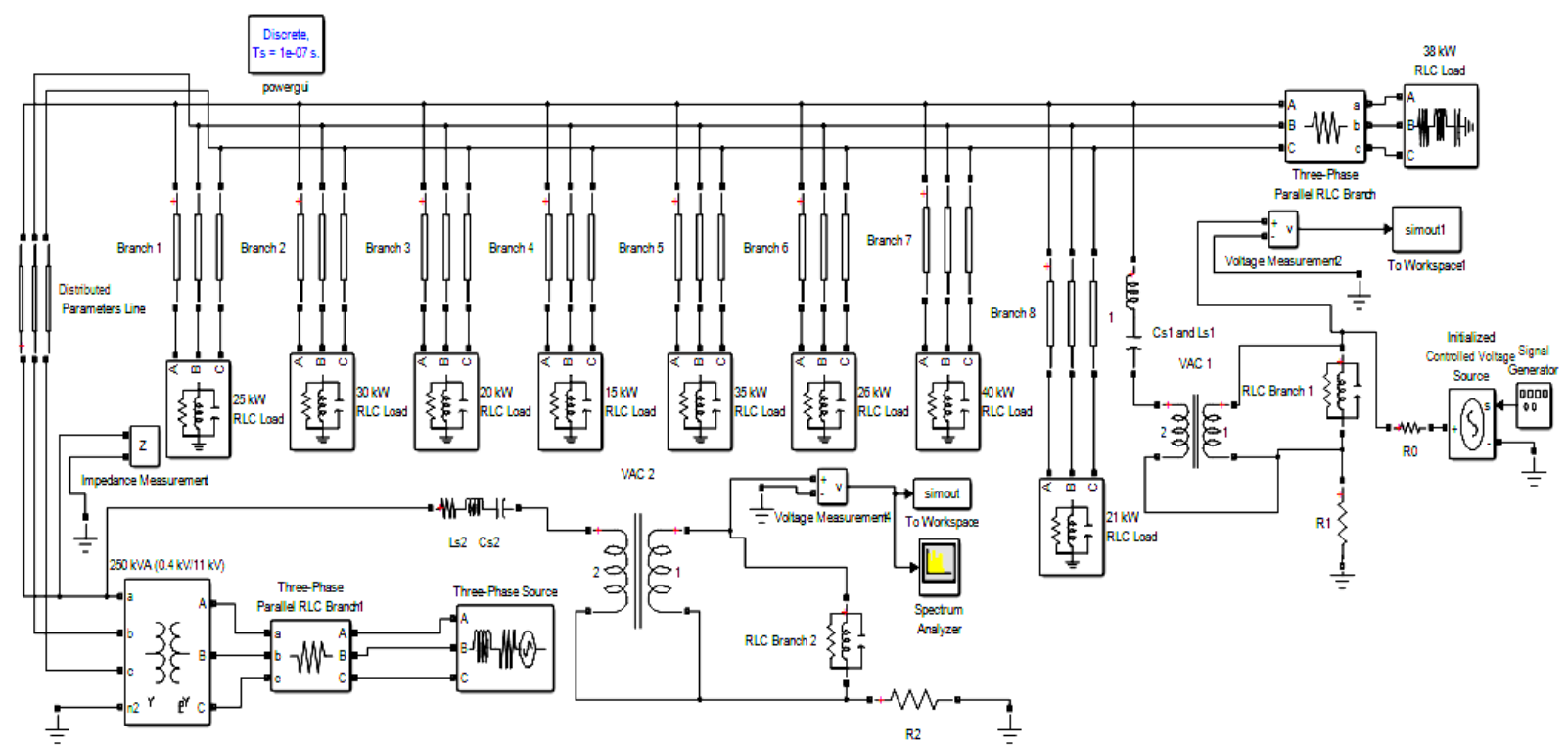

Fig. 6. Simulation model of selected LV electrical network for modeling

$\mathrm{Z}_{\mathrm{C}} \sinh (\gamma l), \frac{1}{Z_{C}} \sinh (\gamma l)$ and $\cosh (\gamma l)$ respectively as given in equation 12 .

Transfer functions of NB-PLC channel based on TL theory by considering constant and frequency selective impedances are obtained by using Eq. 13 and then compared with the transfer function obtained from proposed Simulink model that is analyzed in Section 3, subsequent to the discussion of Simulink model in the following section.

\subsection{SIMULINK model of NB-PLC system}

This research work focuses on developing an NB-PLC channel model which is simulated using Simulink. The LV distribution network represented in this model is based on the standard network values followed by electric supply companies in Pakistan, tabulated in Table 1. Fig. 6 illustrates the proposed Simulink model.

The signal is injected in the phase A of LV network between branch (bridge tap) 8 and $38 \mathrm{~kW}$ RLC load and received on the same phase, at the LV side of $250 \mathrm{kVA}$ transformer using a capacitive coupler to facilitate injection and receiving of communication signal on both the transmitting and receiving ends as shown in Fig. 6. The received signal spectrum is analyzed at spectrum analyzer. The same signal at the same position can be injected in the phases $\mathrm{B}$ and $\mathrm{C}$ and received in their corresponding same phase. The length of LV distribution lines ranges from 60$150 \mathrm{~m}$. The voltage levels and conductor type of selected LV access network consist of $400 V_{L-L}, 230 V_{L-N}$ via $11 \mathrm{kV} /$ $0.4 \mathrm{kV}$ transformer, based on AAC, standard BS-215. In this proposed Simulink channel model the length of main channel is $150 \mathrm{~m}$ terminated to a $38 \mathrm{~kW}$ load with number
Table 2. Active Power (W) and Reactive Power (VAR) Ratios of each RLC load connected to LV network for simulink model

\begin{tabular}{c|c|c|c}
\hline $\begin{array}{c}\text { Sr. } \\
\text { No. }\end{array}$ & $\begin{array}{c}\text { Active power } \\
\text { in watts }\end{array}$ & $\begin{array}{c}\text { Capacitive reactive } \\
\text { power } Q_{\mathrm{C}} \text { in }+ \text { VAR }\end{array}$ & $\begin{array}{c}\text { Inductive reactive } \\
\text { power } \mathrm{Q}_{\mathrm{L}} \text { in -VAR }\end{array}$ \\
\hline 1 & $25 \mathrm{~kW}$ & 38 & 95 \\
\hline 2 & $30 \mathrm{~kW}$ & 40 & 98 \\
\hline 3 & $20 \mathrm{~kW}$ & 35 & 45 \\
\hline 4 & $15 \mathrm{~kW}$ & 32 & 40 \\
\hline 5 & $35 \mathrm{~kW}$ & 43 & 98 \\
\hline 6 & $26 \mathrm{~kW}$ & 40 & 95 \\
\hline 7 & $40 \mathrm{~kW}$ & 45 & 100 \\
\hline 8 & $38 \mathrm{~kW}$ & 42 & 100 \\
\hline
\end{tabular}

of branches or bridge taps emanating from it, each of which has $15 \mathrm{~m}$ length.

A distributed parameter line (DPL) is used to characterize the properties of LV access channel. The parametric values incorporated in DPL and 8 branches are taken from Table 1. After careful investigation about the frequency selective behavior of domestic loads, RLC loads are used in the simulation model [20]. The values of RLC loads connected to each branch ranges from 20-40 $\mathrm{kW}$ in which inductive nature of load is dominating by the ratios of consumed inductive reactive power $Q_{L}$ and capacitive reactive power $Q_{C}$ as tabulated in Table 2. A three phase, two winding, $50 \mathrm{~Hz}$ transformer is used in the Simulink model that has resistance and inductance of winding $1,4.32 \Omega$ and $0.45 \mathrm{H}$ respectively whereas winding 2 resistance and inductance are $0.79 \Omega$ and $0.08 \mathrm{H}$ respectively. The transformer has magnetization resistance $R_{m}, 1.8 \mathrm{M} \Omega$ and magnetization inductance $L_{m} 500 \mathrm{H}$, supplied by $\mathrm{Y}$ connected three phase, $11 \mathrm{kV}$ source with $\mathrm{X} / \mathrm{R}$ ratio of 7 . 
Table 3. Model parameters of capacitive coupling device

\begin{tabular}{|c|c|c|c|c|c|c|c|}
\hline \multicolumn{2}{|c|}{$\begin{array}{c}\text { LV Series } \\
\mathrm{L}_{\mathrm{s}} \mathrm{C}_{\mathrm{s}} \\
\text { parameters }\end{array}$} & \multicolumn{3}{|c|}{$\begin{array}{l}\text { RLC Branch } \\
\text { parameters }\end{array}$} & \multicolumn{3}{|c|}{ Isolation transformer } \\
\hline $\begin{array}{c}\mathrm{L}_{\mathrm{S}} \\
{[\mu \mathrm{H}]}\end{array}$ & $\begin{array}{c}\mathrm{C}_{\mathrm{S}} \\
{[\mathrm{nF}]}\end{array}$ & $\begin{array}{c}\mathrm{R} \\
{[\mathrm{k} \Omega]} \\
\end{array}$ & $\begin{array}{c}\mathrm{L} \\
{[\mu \mathrm{H}]}\end{array}$ & $\begin{array}{c}\mathrm{C} \\
{[\mathrm{nF}]}\end{array}$ & $\begin{array}{c}\text { Turn } \\
\text { Ratio } \\
\end{array}$ & $\begin{array}{c}\text { Magnetization } \\
\text { resistance, } \mathrm{R}_{\mathrm{M}}[\Omega]\end{array}$ & $\begin{array}{c}\text { Inductance, } \\
\mathrm{L}_{\mathrm{T}}[\mu \mathrm{H}] \\
\end{array}$ \\
\hline 68 & 82 & 30 & 165 & 14 & $1: 1$ & 75 & 450 \\
\hline
\end{tabular}

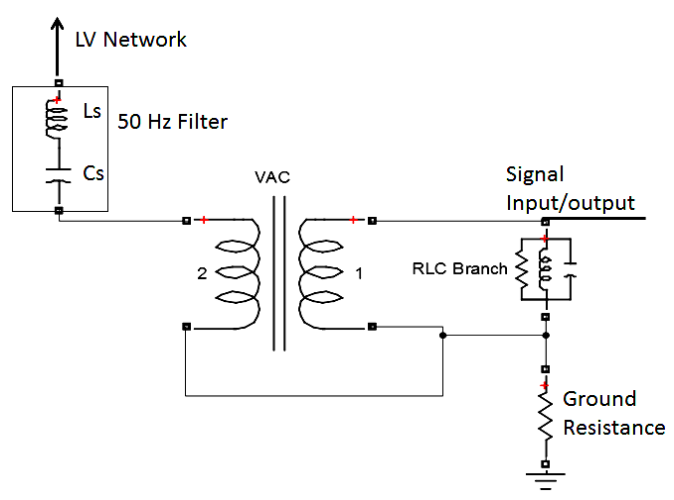

Fig. 7. Schematic of LV phase to ground capacitive coupling device

\subsection{Capacitive coupling device}

Signal injection is not possible without a properly designed coupling device [3]. A schematic of capacitive coupler of LV phase to ground is illustrated in Fig. 7. A sinusoidal signal generator gives a $1 \mathrm{~V}$ signal to parallel RLC circuit followed by isolation transformer operating on a frequency range $3-500 \mathrm{kHz}$. Both isolation transformers incorporated at transmitting and receiving, capacitive coupling device are grounded with $1000 \Omega$ resistance.

A $50 \mathrm{~Hz}$ filter is introduced at the output of isolation transformer. The model parameters of capacitive coupling device are tabulated in Table 3. The transceiver coupling interface used at the receiving end has same values as the capacitive coupler of transmitter side. The transfer function plot of capacitive coupling device and LV network (by injecting the signal through capacitive coupling device) is illustrated in Fig. 8 and discussed in the following Section.

\section{NB-PLC Channel Transfer Function-Results and Discussion}

We have modeled an NB-PLC channel using TL theory as discussed in Section 2.1, the transfer functions of which are illustrated in Fig. 8, which shows channel transfer function plots incorporating constant and frequency selective impedances. The mean degree of attenuation in the channel transfer function plots caused by constant impedances is less than that shown by the transfer function plot using frequency selective impedances. The results are compared with transfer function plots achieved from Simulink model shown in Fig. 8. Transfer

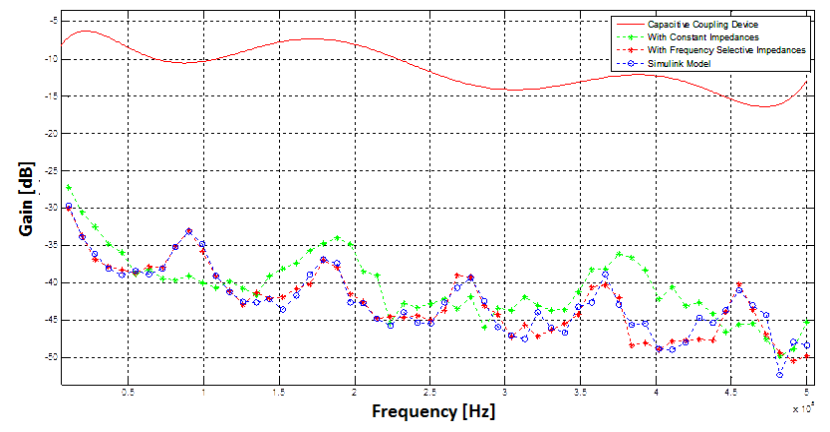

Fig. 8. Transfer function plots obtained from Capacitive coupling device, TL theory (based on constant and frequency selective impedances) and Simulink model

function result obtained by incorporating the frequency selective impedances is more similar with the result obtained from Simulink model. Therefore, the results indicate that incorporating the frequency selective impedance in the network parameters of NB-PLC channel model would give a more accurate representation of the channel.

Both plots (frequency selective impedances and Simulink model) show the deep nulls at the frequencies 50, 125-150, 225-250, 310-340, 410 and $485 \mathrm{kHz}$. However overall simulation plots obtained from Simulink model and frequency selective impedances of TL theory are in good agreement with each other thus validating the proposed procedure and techniques for the characterization and modeling of LV NB-PLC system.

\section{Conclusions}

With the deployment of SG technologies a reliable communication system is the need of the hour that may utilize the ubiquitously available powerline as a communication medium due to its existing infrastructure nationwide. This enhances the emphasis of an accurate channel requirement for design of a reliable communication system specifically for AMI within the SG. This research work focuses on proposing a NB-PLC channel model for LV access network. Channel transfer function results are obtained by utilizing the TL theory and a Simulink model while a capacitive coupling device is designed to inject NB-PLC signal into the LV access network which is found in literature only for a MV network. It has been observed that transfer function plots obtained from Simulink model that has frequency selective nature is approximately comparable with the TL theory transfer function that is based on frequency selective impedances but when it comes to compare with the constant impedances based transfer function of TL theory, lesser attenuations were observed. Our proposed Simulink NB-PLC channel model can be a useful tool to model any LV access network channel conditions by varying the network parameters. 


\section{References}

[1] Joseph Vardi and Benjamin Avi-Itzhak, Electric Energy Generation; Economics, Reliability and Rates: MIT, 1981, p.75-94.

[2] Roy Billinton and Easin Khan, "A Security Based Approach to Composite Power System Reliability Evaluation," IEEE Trans. Power Systems, vol. PS-7, no. 1, pp. 65-72, Feb. 1992.

[3] Jaeseok Choi, Hongsik Kim, Junmin Cha and Roy Billinton, "Nodal Probabilistic Congestion and Reliability Evaluation of a Transmission System under the Deregulated Electricity Market," in Proceedings of IEEE PES SM2001 Conference, Vancouver, Canada, July 2001.

[4] T. -E. Sung, A. Scaglione, and S. Galli, "TimeVarying Power Line Block Transmission Models over Doubly Selective Channels," in IEEE International Symposium on Power Line Communications and Its Applications, 2008.

[5] T. Banwell and S. Galli, "A Novel Approach to the Modeling of the Indoor Power Line Channel Part I: Circuit analysis and Companion Model," IEEE Transactions on Power Delivery, vol. 20 No. 2, 2005.

[6] S. Galli and T. Banwell, "A novel approach to the modeling of the indoor power line channel part II: Transfern function and its properties," IEEE Transactions on Power Delivery, vol. 20 No. 3, 2005.

[7] M. Zimmermann and K. Dostert, "A Multipath Model for the Powerline Channel," IEEE Transactions on Communications, vol. 50 No. 4, 2002.

[8] A. M. Tonello and F. Versolatto, "Bottom-Up Statistical PLC Channel ModelingPart I: Random Topology Model and Efficient Transfer Function Computation," IEEE Transactions on Power Delivery, vol. 26, No. 2, 2011.

[9] A. M. Tonello and F. Versolatto, "Bottom-Up Statistical PLC Channel Modeling Part II: Inferring the Statistics," IEEE transactions on Power Delivery, vol. 25, Issue: 4, pp. 2356-2363, 2010.

[10] A. M. Tonello and F. Versolatto, "New Results on Topdown and Bottom-up Statistical PLC Channel Modeling," in Third workshop on Power Line Communications, 2009.

[11] J. Anatory, N. Theethayi, and R. Thottappillil, "PowerLine Communication Channel Model for Interconnected NetworksPart I: Two-Conductor System," IEEE Transactions on Power Delivery, vol. 24 No. 1, 2009.

[12] J. Anatory, N. Theethayi, and R. Thottappillil, "PowerLine Communication Channel Model for Interconnected NetworksPart II: Multiconductor System," IEEE Transactions on Power Delivery, vol. 24 No. 1, 2009.

[13] F. J. C. ete, J. A. Corts, L. Dez, and J. T. Entrambasaguas, "A channel model proposal for indoor Power Line Communications," IEEE Communications Magazine, 2011.

[14] B. Masood and S. Baig, "Channel Modeling of NBPLC for Smart Grid," in IEEE Symposium on Computers and Communications (ISCC), 2015.

[15] J. N. Hendrik C. Ferreira, Lutz Lampe and T. G. Swart, Power Line Communication: Theory and Applications for Narrowband and Broadband Communications over Power Lines. John Willey \& Sons, 2010.

[16] M. Antoniali and A. M. Tonello, "Measurement and characterization of load impedances in home Power Line Grids," IEEE transactions on instrumentation and measurement, vol. 63, no. 8, pp. 548-556, 2014.

[17] R. Lefort, B.Taquet, R. Vauzelle, V. Courtecuisse, A. M. Poussard, and N. Idir, "High frequency MV/LV transformer modelling for Power Line Communication applications," in 18th IEEE International Symposium on Power Line Communications and Its Applications, 2014.

[18] A. M. Tonello, A. Petolo, and M. Girotto, "Power Line Communication: Understanding the channel for physical layer evolution based on filter bank modulation," IEICE Trans. Communication, vol. E97B, No, 8, 2014.

[19] J. Matanza, S. Alexandres, and C. Rodrguez-Morcillo, "Advanced metering infrastructure performance using European low-voltage power line communication networks," IET Commun., vol. 8, Iss. 7, p. 10411047, 2014.

[20] J. Bausch, T. Kistner, M. Babic, and K. Dostert, "Characteristics of indoor power line channels in the frequency range $50-500 \mathrm{kHz}$," in IEEE International Symposium on Power Line Communications and Its Applications, 2006.

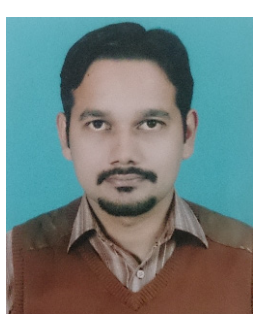

Bilal Masood He was born in Lahore, Pakistan, in 1984. He received BS and MS in Electrical Engineering from The University of Lahore, Lahore, Pakistan in 2008 and 2010 respectively. He is pursuing his $\mathrm{PhD}$ degree in Electrical Engineering from COMSATS Institute of Information Technology, Lahore, Pakistan. His research interests include opportunities and challenges of ICT in Smart Grid.

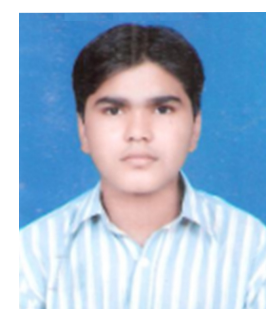

Arsalan Haider He received B. Sc. in Electrical Engineering from The Superior College, University Campus, Lahore, Pakistan in 2016. His research interests include the Renewable Energy Systems and Smart Metering using Power Line Communications. 


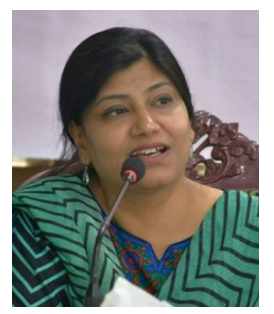

Sobia Baig She is the Head of Department/Associate Professor at the Department of Electrical Engineering, COMSATS Institute of Information Technology, Lahore, Pakistan. She holds a B.Sc. in Electrical Engineering from University of Engineering and Technology (UET), Taxila, Pakistan and M.S. and Ph.D. in Electronic Engineering from GIK Institute of Engineering Sciences and Technology, Topi, Pakistan in 2008. Her research interests include Smart Grid Communication techniques, multicarrier modulation techniques and application of wavelet based modulation techniques in the wireline Digital Subscriber Line (DSL) and power line communication (PLC) networks. She has done several years of voluntary work with IEEE in Pakistan and currently holds the position of Vice-Chair, IEEE Lahore Section. She has a wide teaching experience in higher education at both undergraduate and graduate levels. 